\title{
Therapie nach Maß für Asthmatiker
}

In der Therapie bei Asthma bronchiale gilt auch nach der neuen GINA-Leitlinie ein Stufenschema. Lichtblicke gibt es für Patienten mit schwerem Asthma.

Die Behandlung bei Asthma besteht aus zwei Strategien: Der Bedarfstherapie zur akuten Symptomkontrolle (Reliever) und der Dauertherapie zur Krankheitskontrolle (Controller). Das aktuelle Stufenschema der Global Initiative for Asthma (GINA) empfiehlt eine schrittweise Eskalation der Therapie, bis eine möglichst vollständige Asthmakontrolle erreicht ist.

\section{DATEN UND FAKTEN}

\section{$31 \%$}

der KHK-Patienten mit plötzlichem Herztod, aber nur 13\% der KHK-Patienten ohne plötzlichen Herztod hatten in einer Studie eine COPD [1]. Die Studienautoren folgern aus ihren Ergebnissen, dass es einen von der KHK unabhängigen Zusammenhang zwischen COPD und plötzlichem Herztod geben müsse. Als Mechanismus komme unter anderem ein durch die COPD induziertes, rechtsventrikuläres Remodelling in Frage.

[1] JACCCEP 2015; 1(5): 381-387

\section{INFOS IM INTERNET}

Alle Folgen der Sommer-Akademie finden Sie im Web unter www.aerztezeitung.de

Auf www.goldcopd.org gibt die Global Initiative for Chronic Obstructive Lung Disease viele Informationen zu COPD, unter anderem auch zu ACOS (Asthma-COPD Overlap Syndrom). Hier ist auch die aktuelle Leitlinie zu finden.

Die aktuelle Leitlinie der Global Initiative for Asthma (GINA) mit Empfehlungen zur Diagnostik und Therapie steht auf: www.ginasthma.org

Praktische Infos zu Asthma/COPD für Ärzte und Patienten bietet die Deutsche Atemwegsliga auf ihrer Website: www.atemwegsliga.de
Stufe 1. Es wird zunächst eine alleinige Bedarfstherapie mit einem kurzwirksamen Bronchodilatator („short acting beta-agonist“, SABA) als Reliever empfohlen; alternativ kann bereits in dieser Stufe der Einsatz eines niedrigdosierten inhalativen Kortikosteroids (ICS) als Controller erwogen werden [1].

Stufe 2. Ab dieser Stufe, wenn also zum Beispiel eine Bedarfstherapie häufig genutzt wird, wird eine ICS-Therapie als Controller der ersten Wahl empfohlen; als alternative Controller werden Montelukast oder Theophyllin genannt.

Stufe 3. Wenn mit der Medikation in Stufe 2 die Krankheit nicht vollständig kontrolliert ist, wird zur Kombination eines ICS mit einem weiteren Controller - bevorzugt einem langwirksamen inhalativen Beta-Agonisten (LABA) geraten; alternativ können auch Montelukast und/oder Theophyllin hinzugefügt werden. Nach der neuen GINA-Leitlinie dürfen ICS/LABA-Kombinationen, sofern sie Formoterol enthalten, ab Stufe 3 auch als Reliever eingesetzt werden (sogenanntes MART-Konzept: „maintenance and reliever therapy“).

Stufe 4. Sie ist dadurch gekennzeichnet, dass die ICS/LABA-Kombinationstherapie bis zur höchsten zugelassenen Dosierung gesteigert wird. Ab Stufe 4 kann auch das langwirksame inhalative Anticholinergikum (LAMA) Tiotropium zur Therapie hinzugefügt werden, welches für diese Indikation im Jahr 2014 in Deutschland zugelassen wurde.

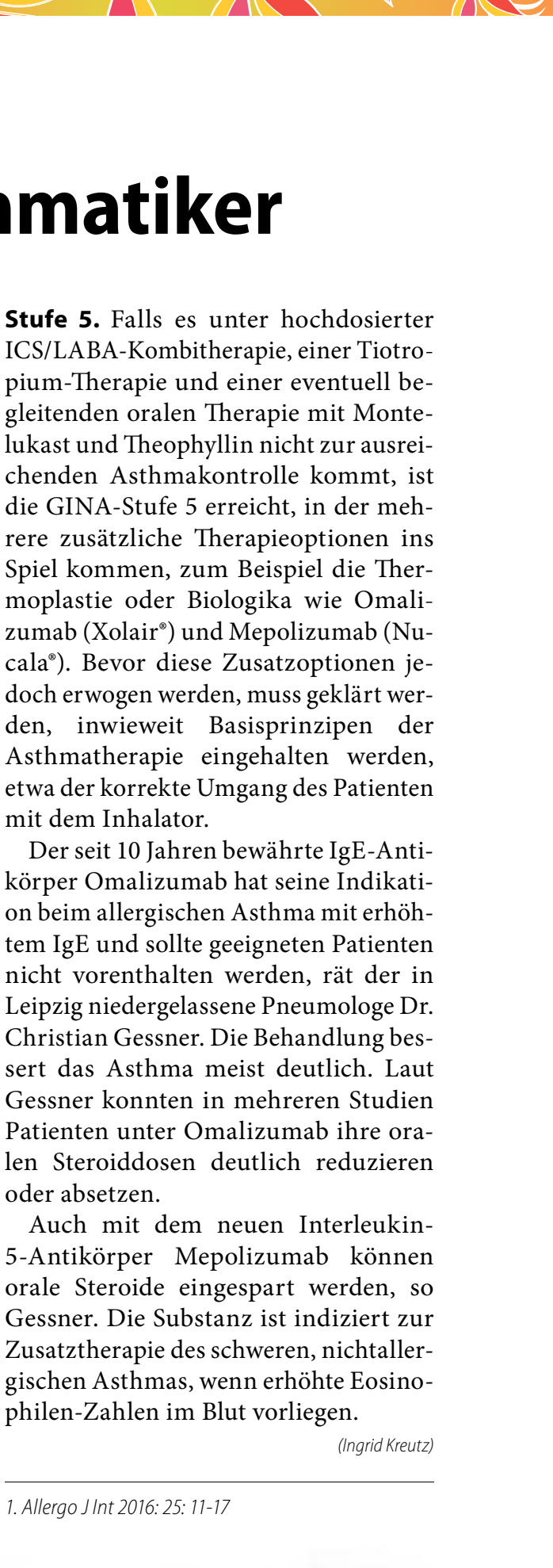

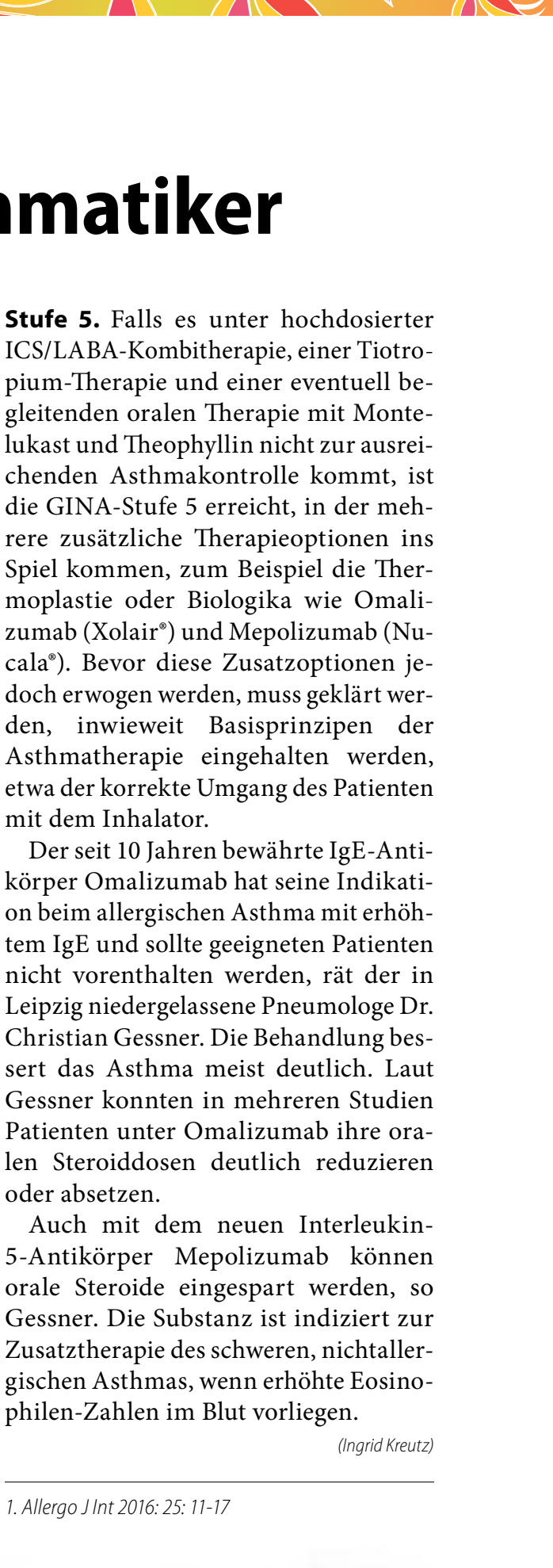

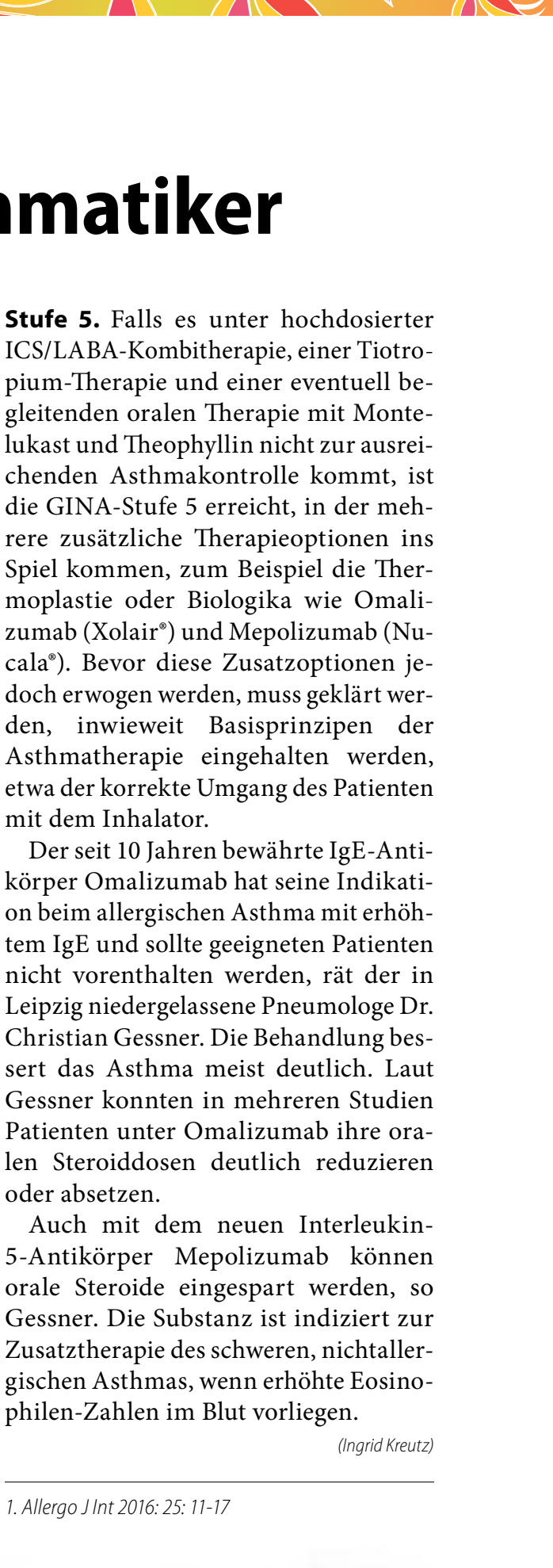

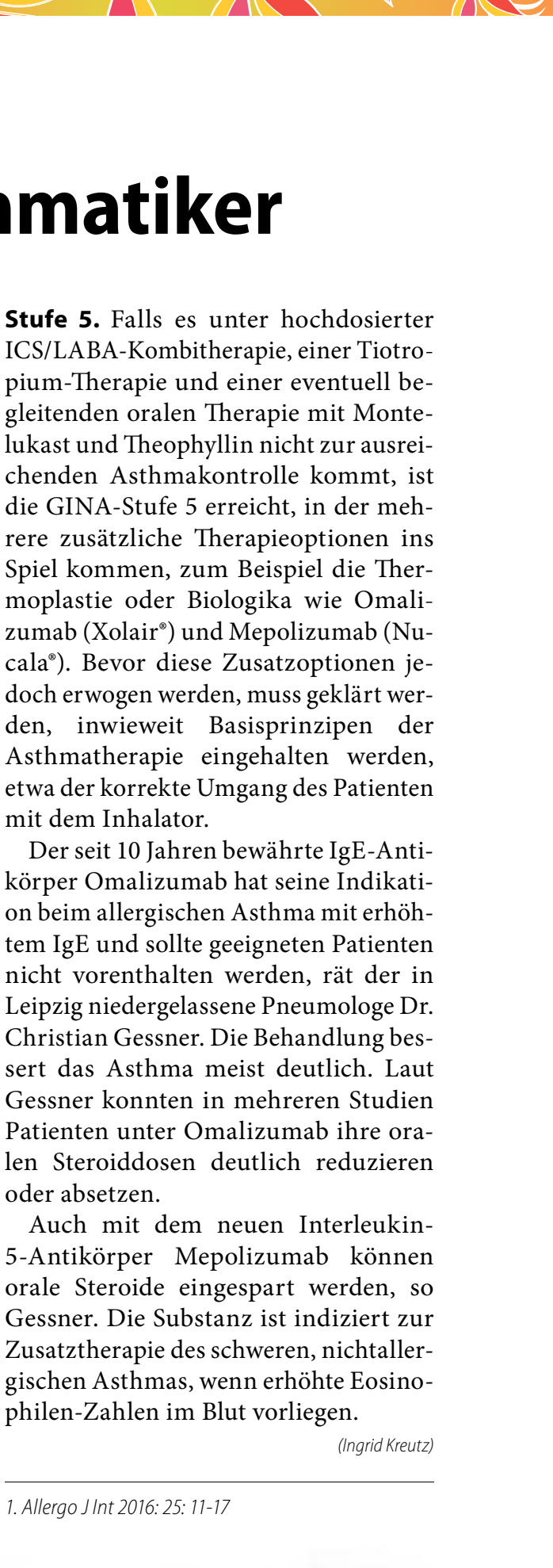

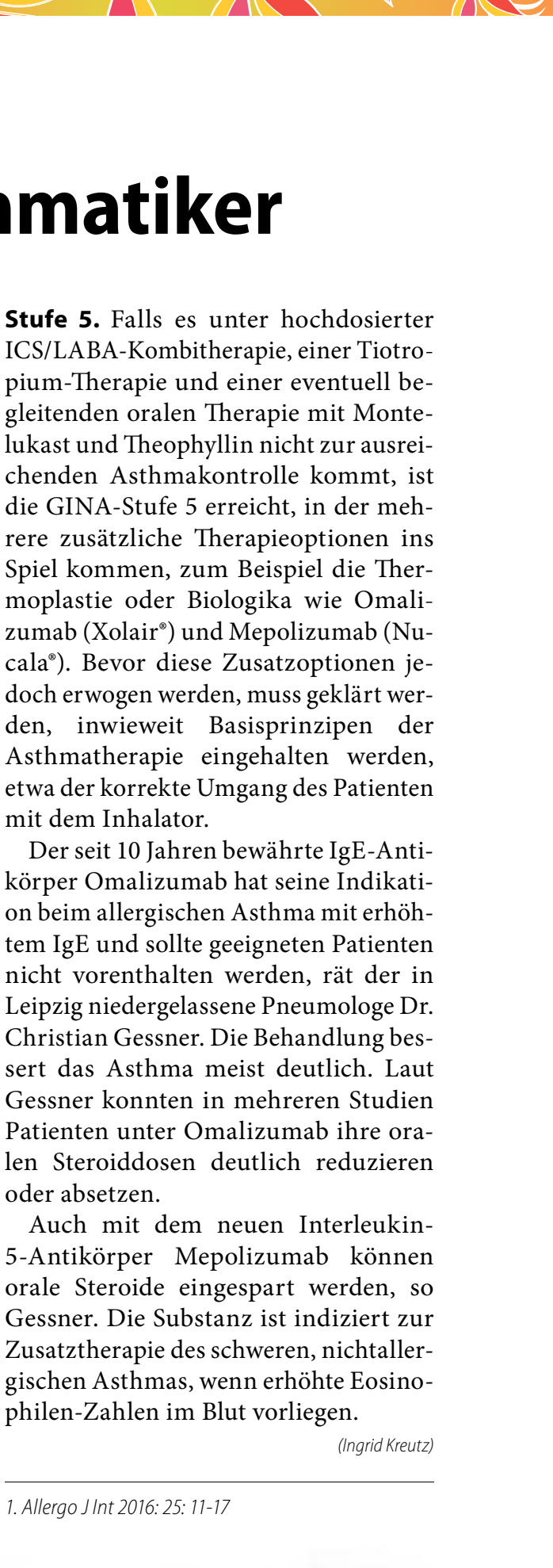

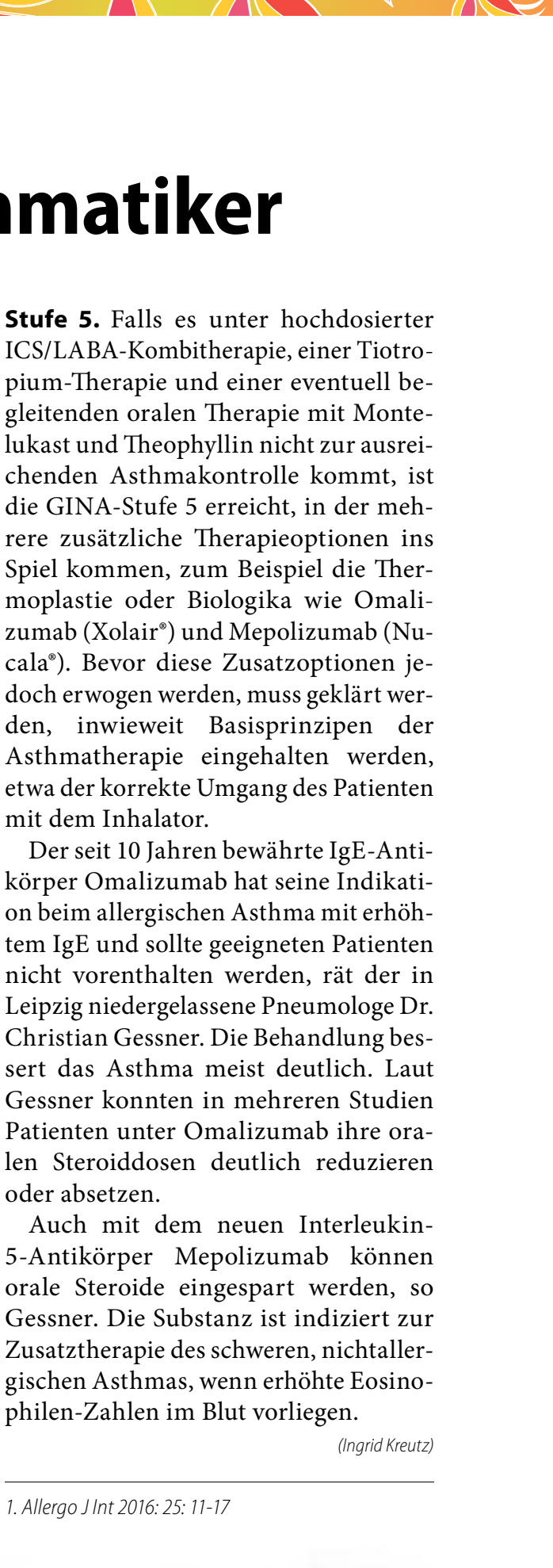

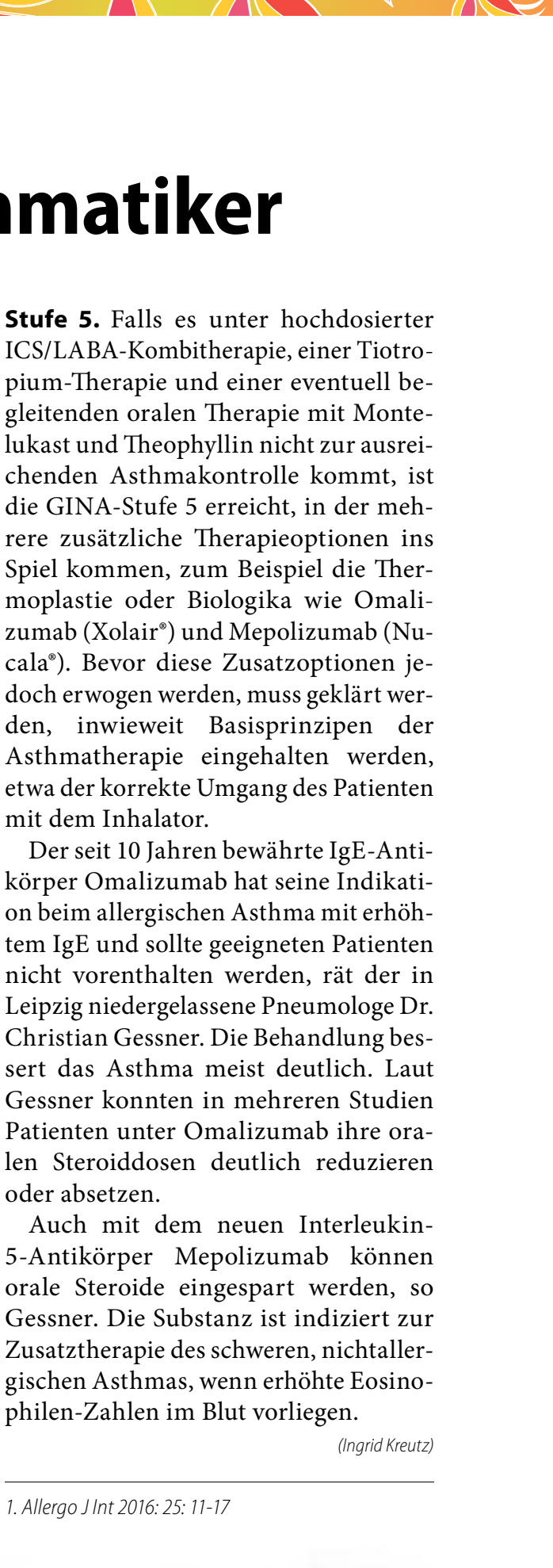

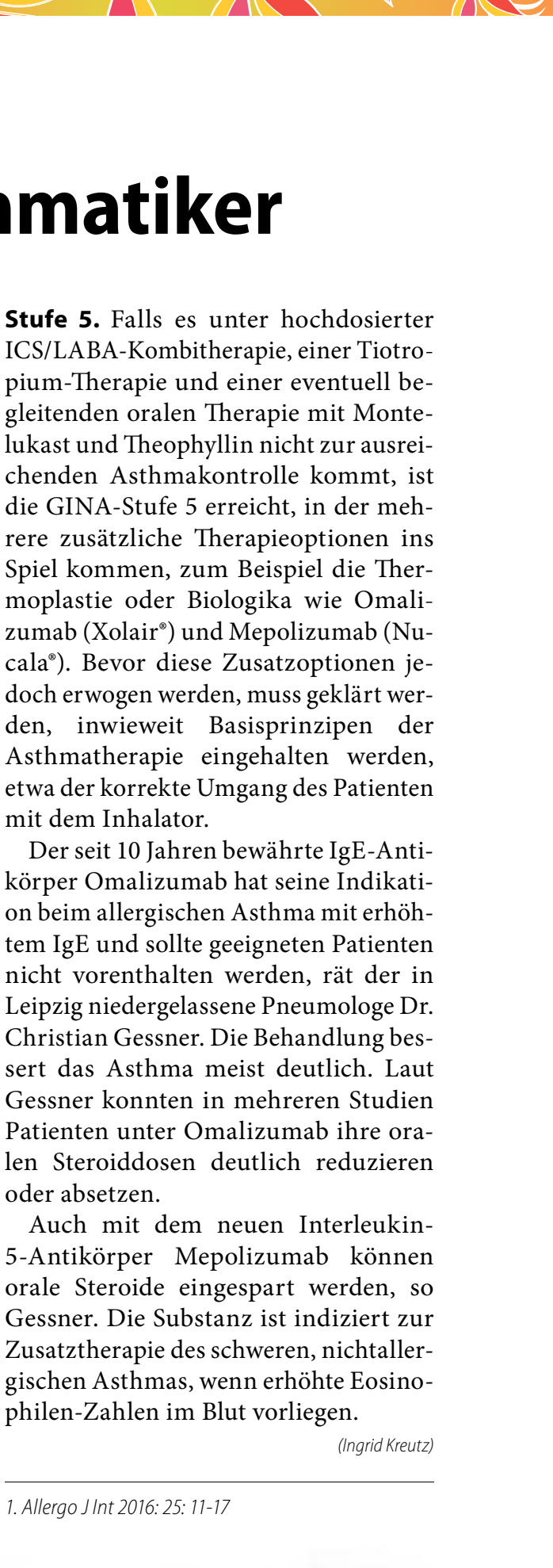

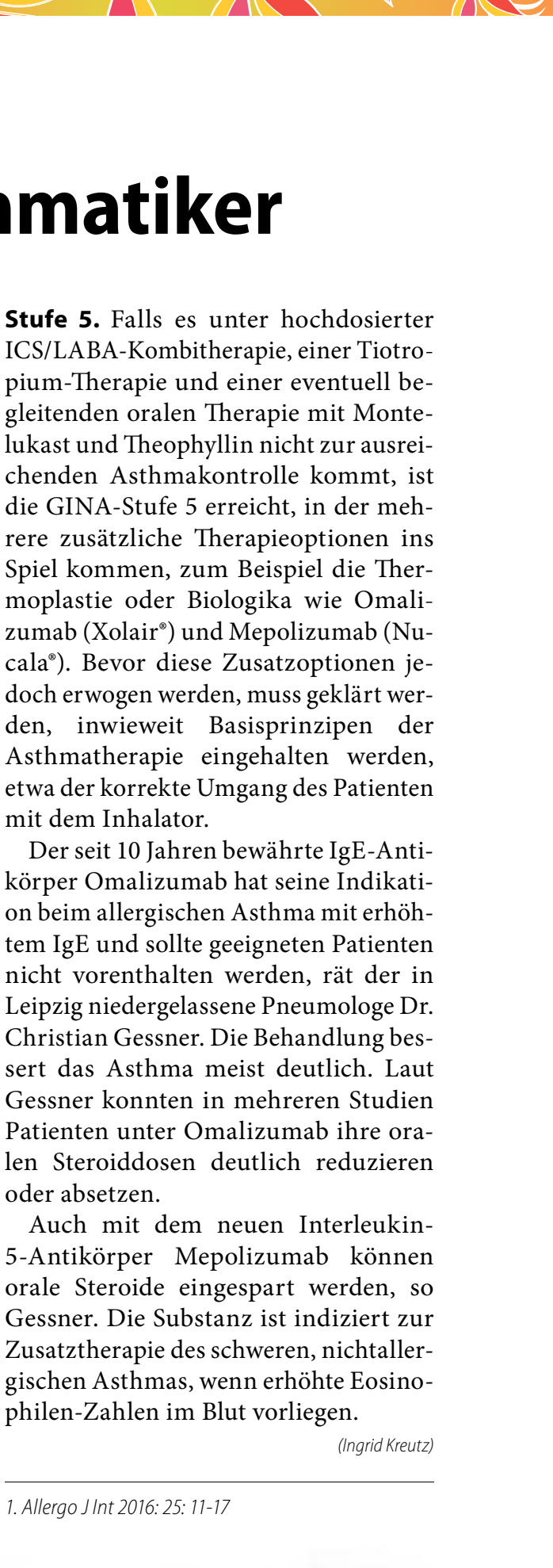

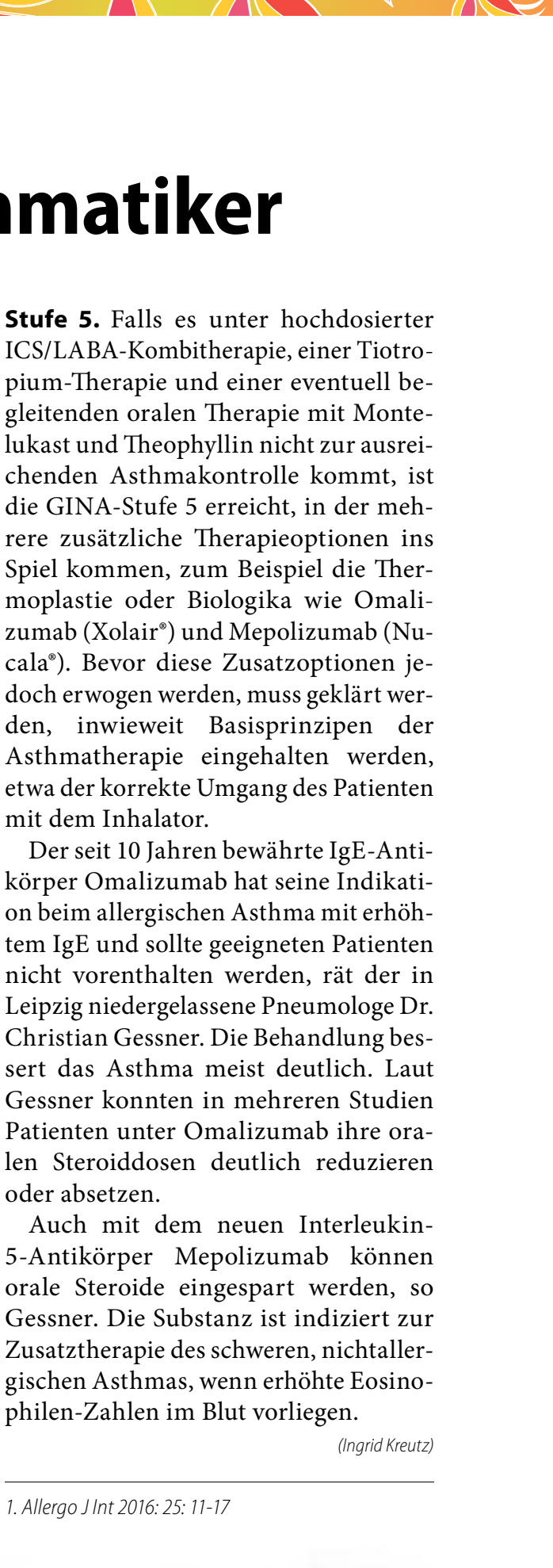

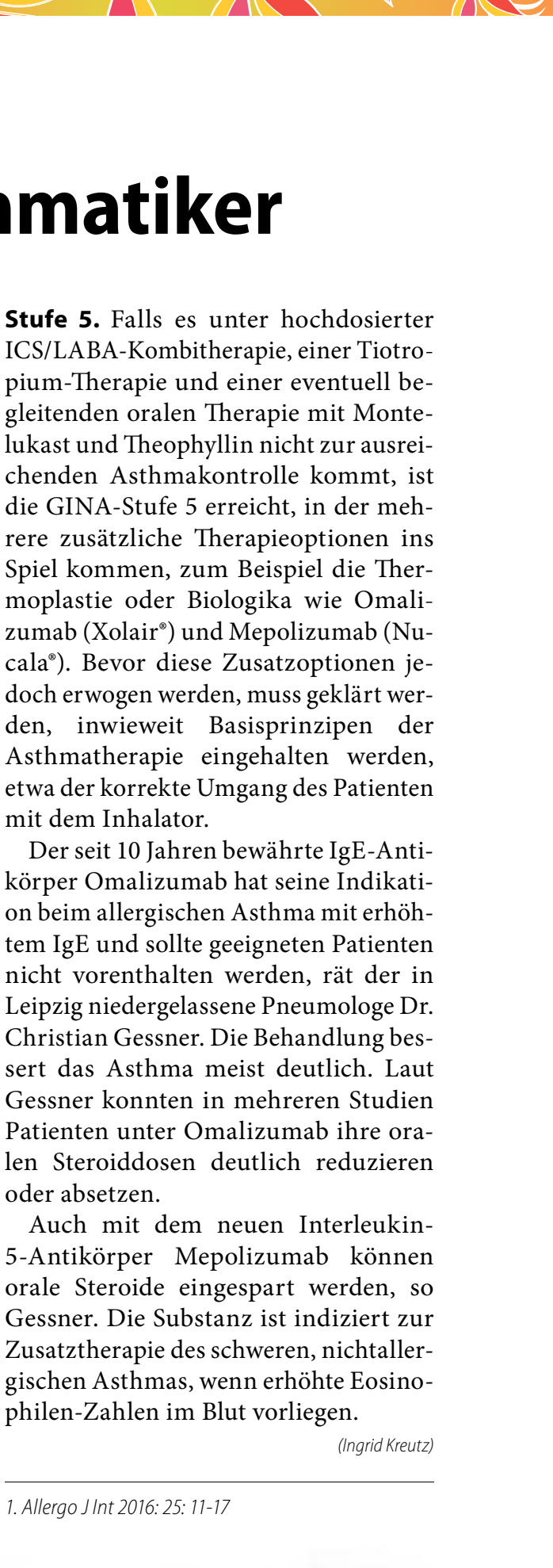

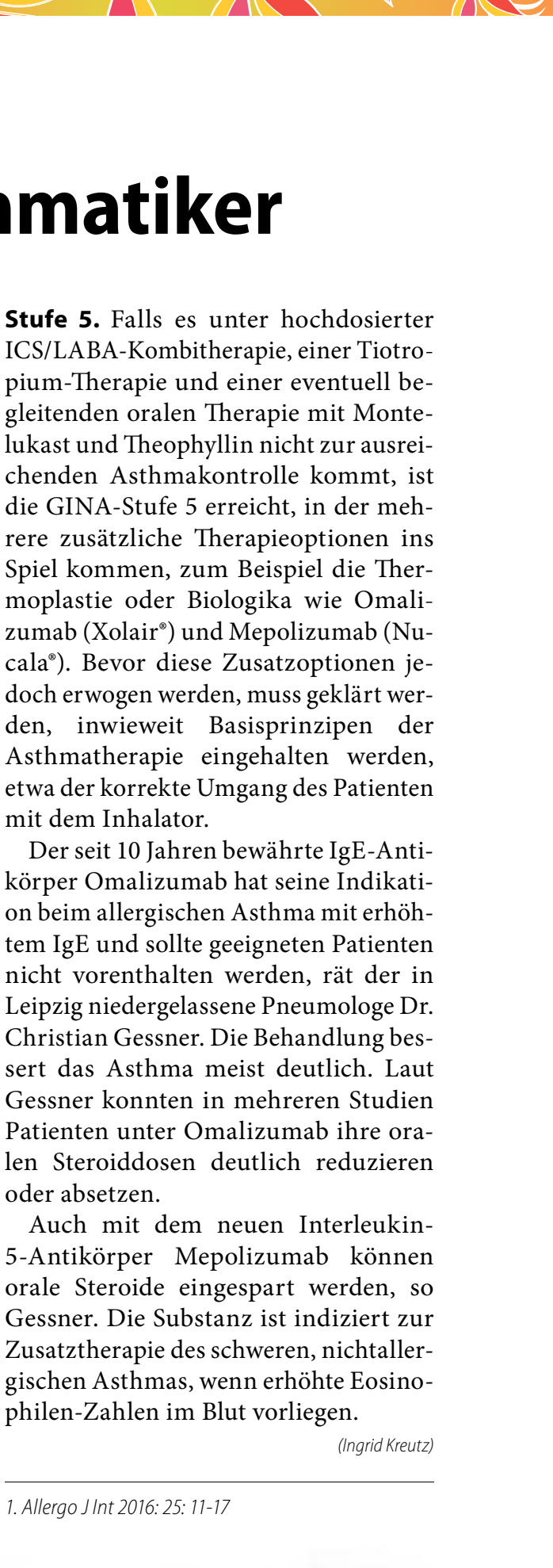

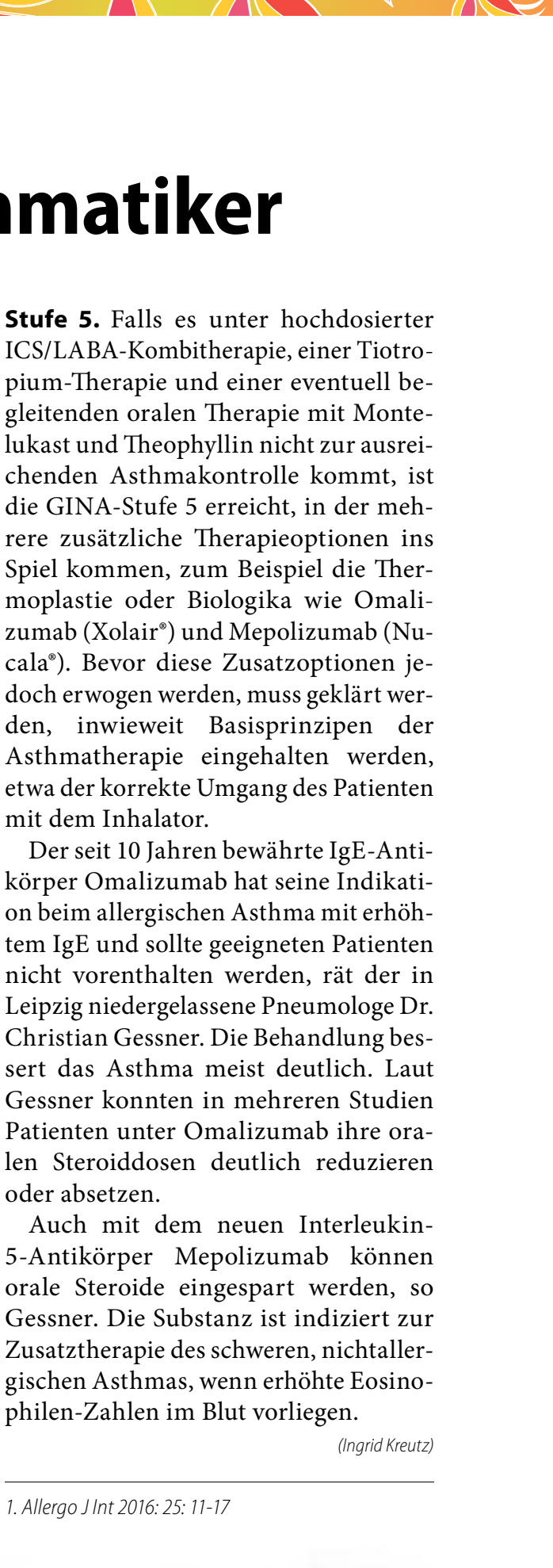

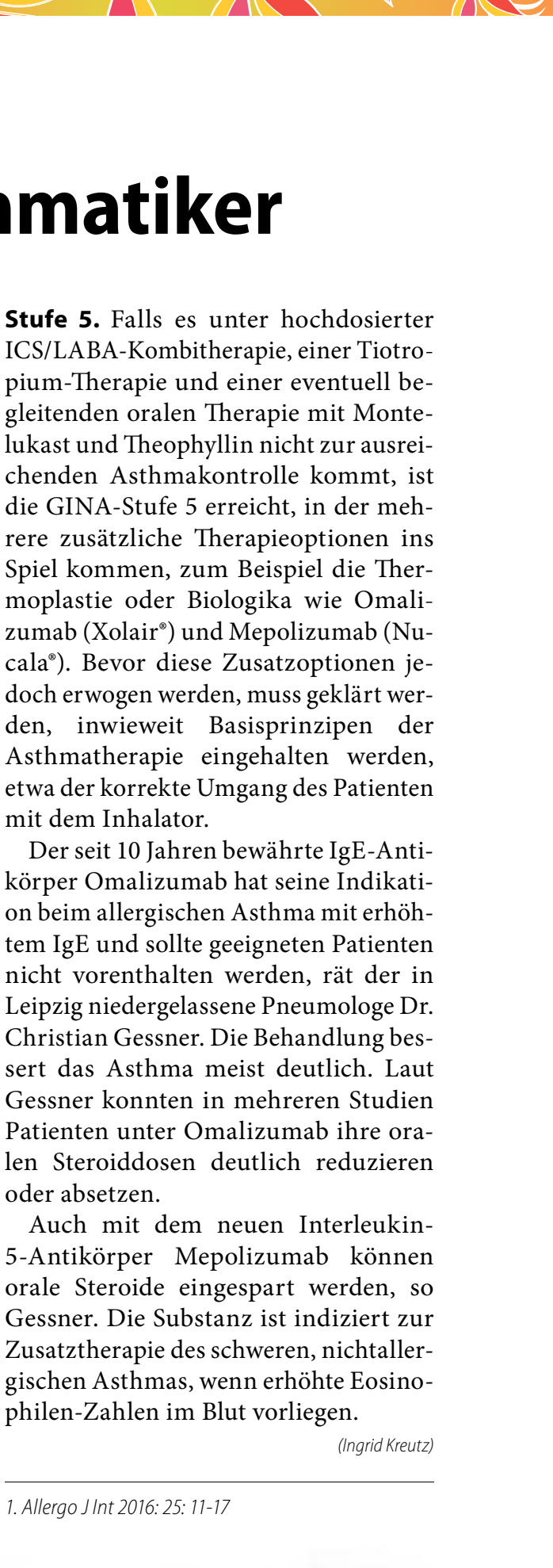

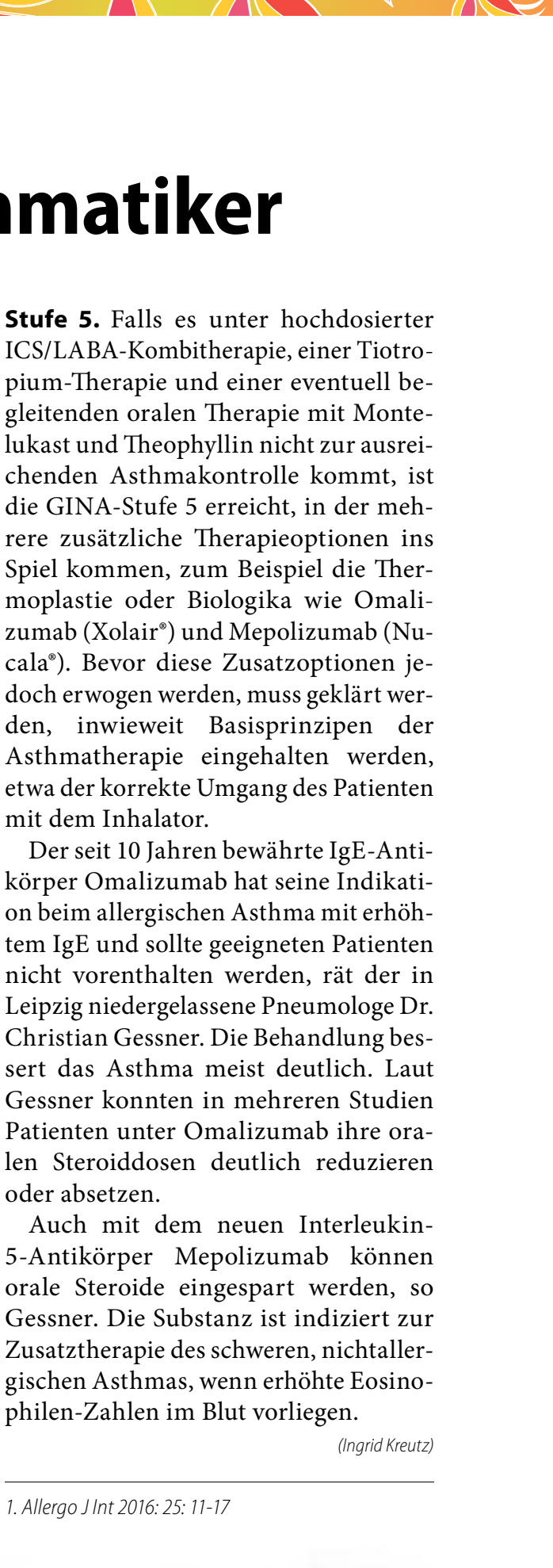

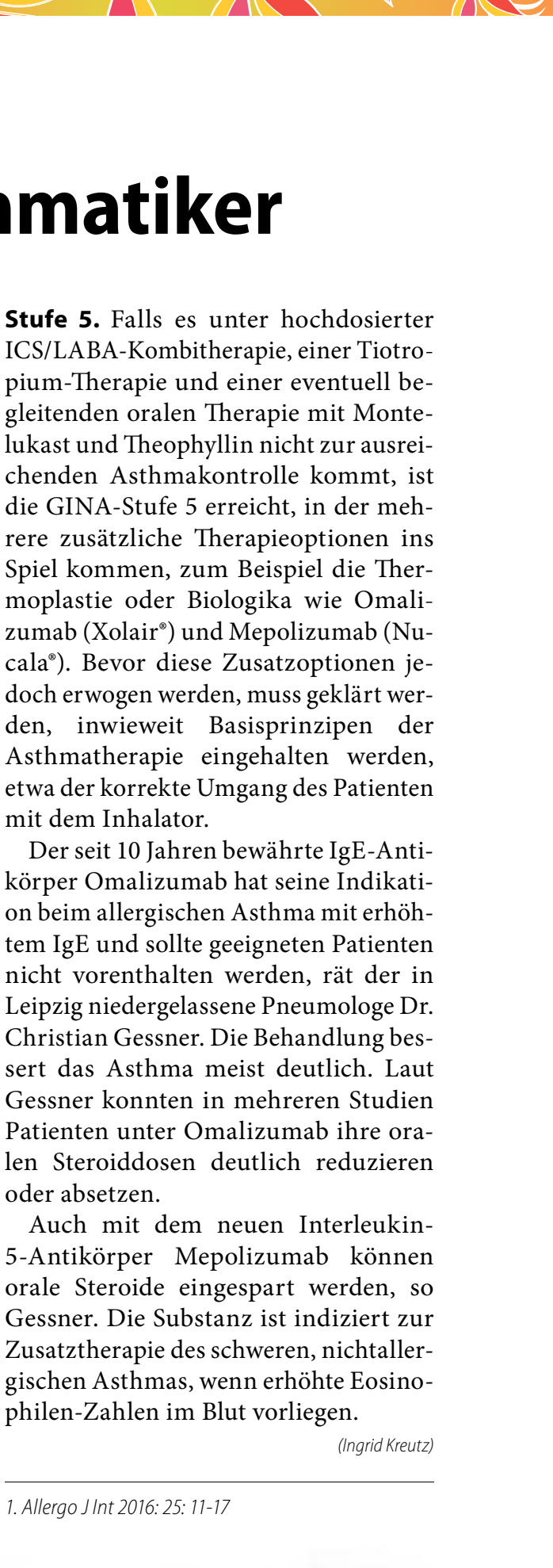

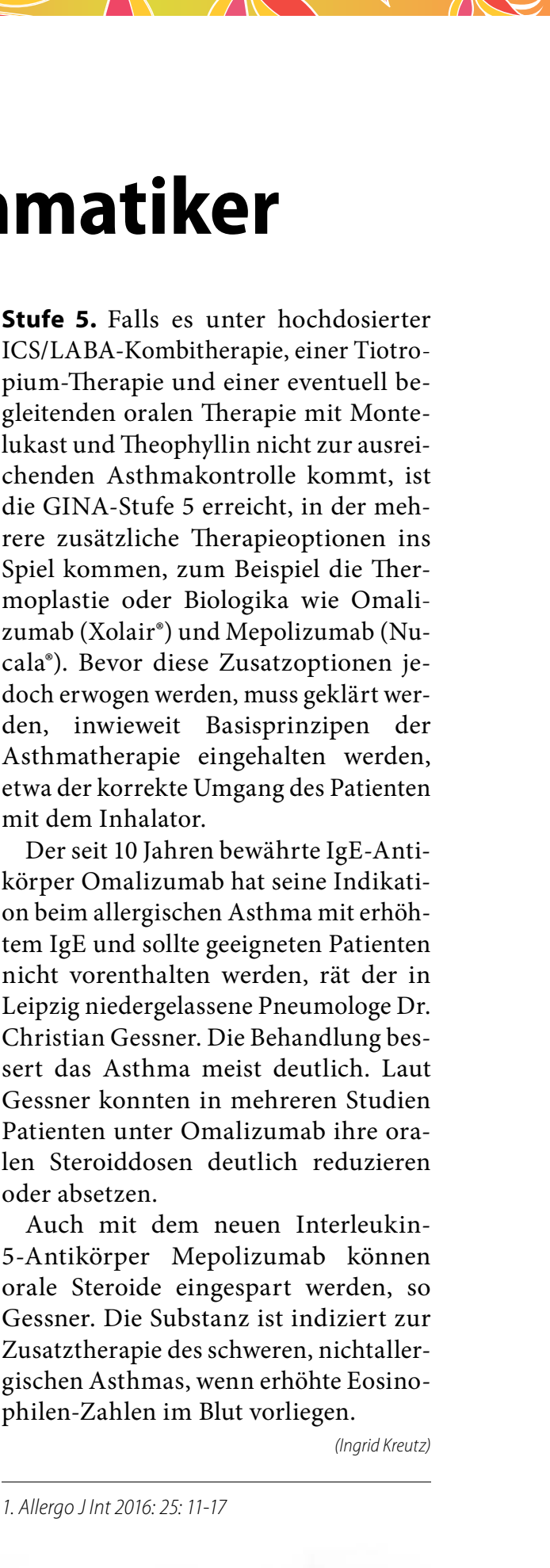

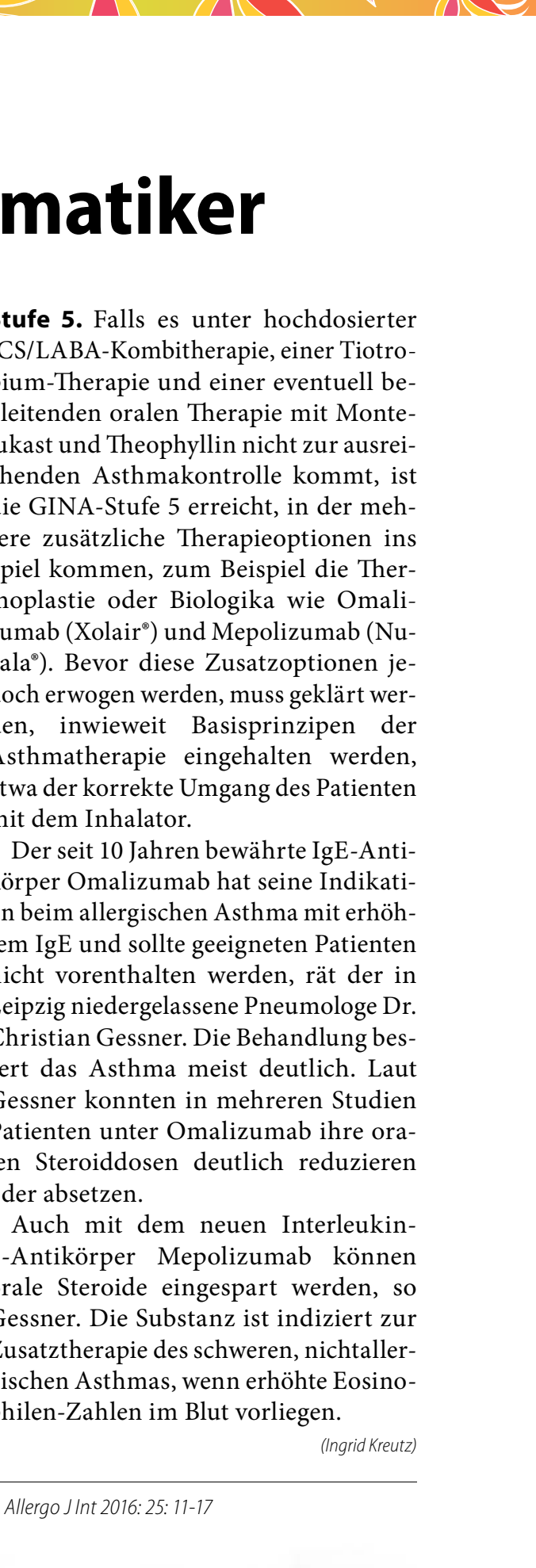

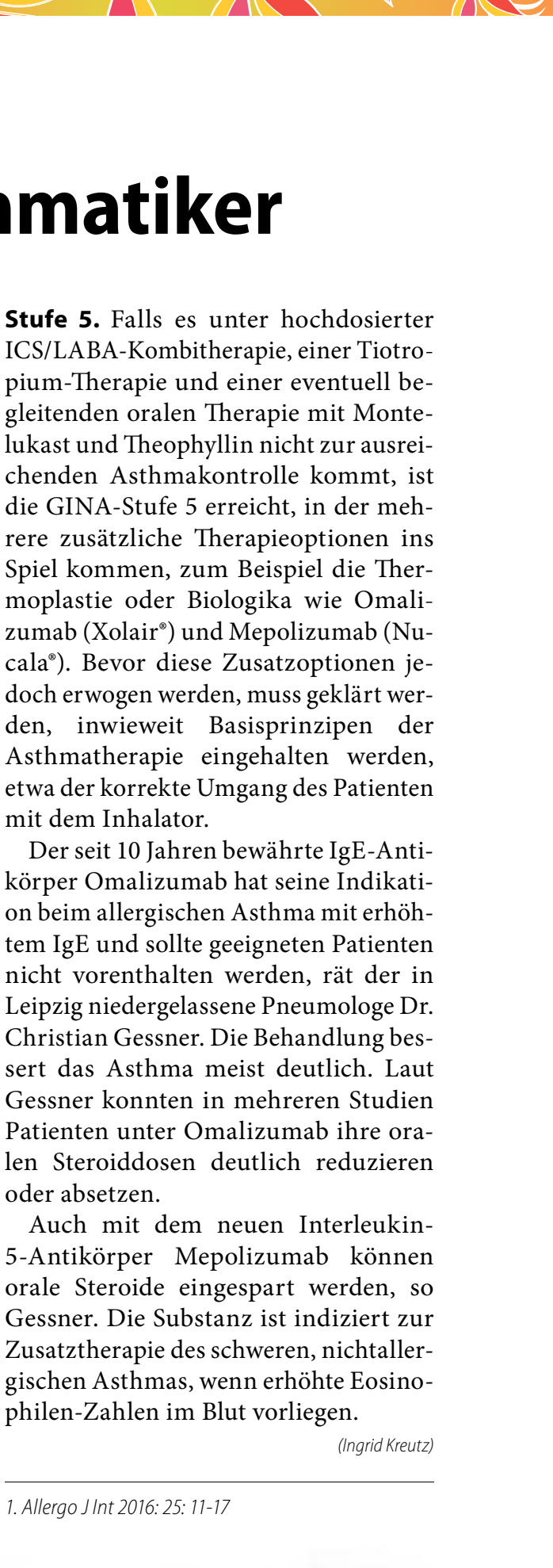

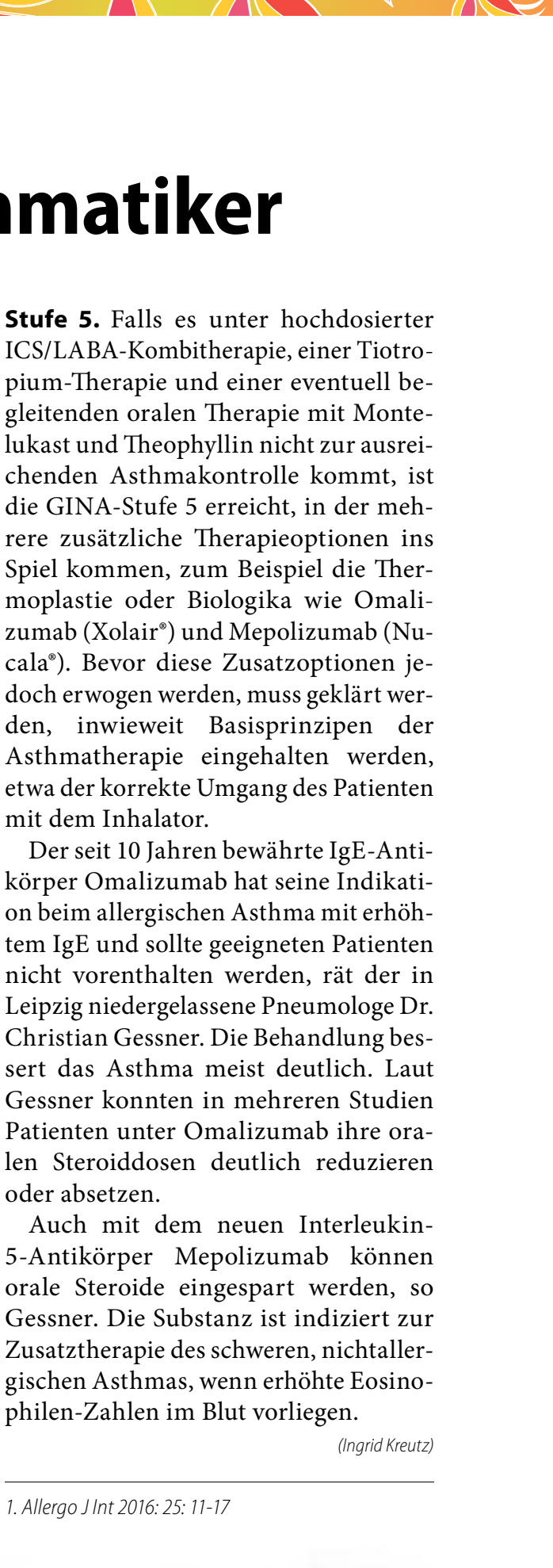

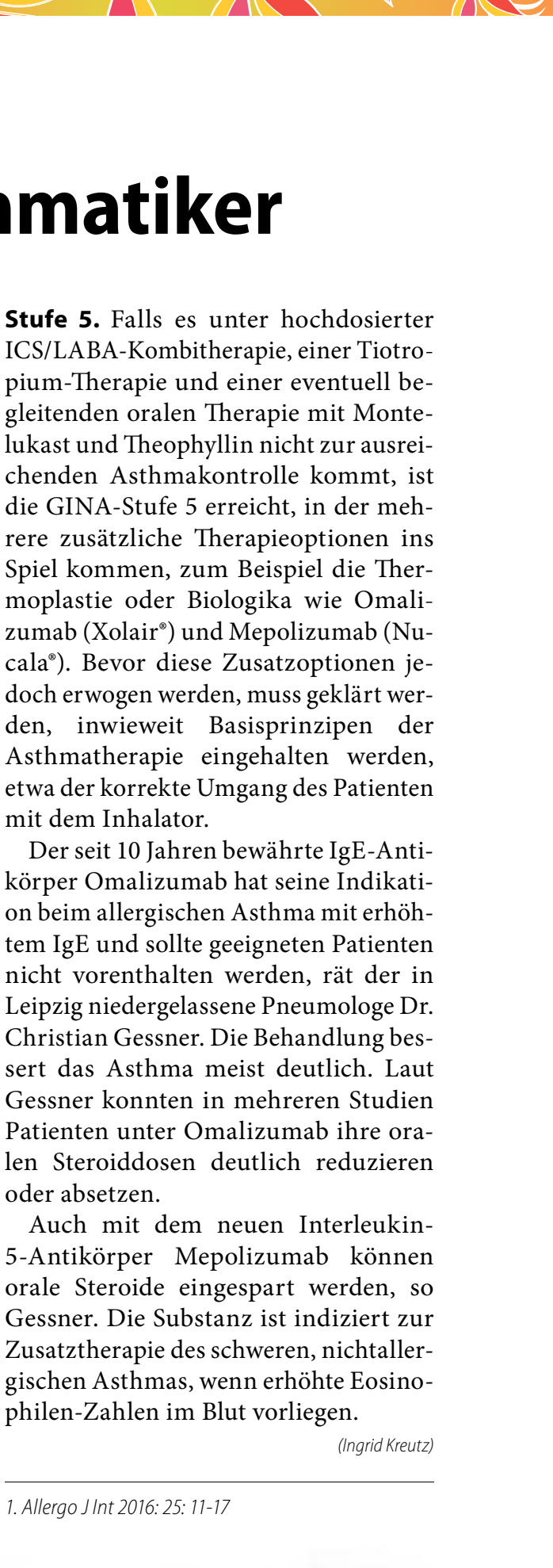

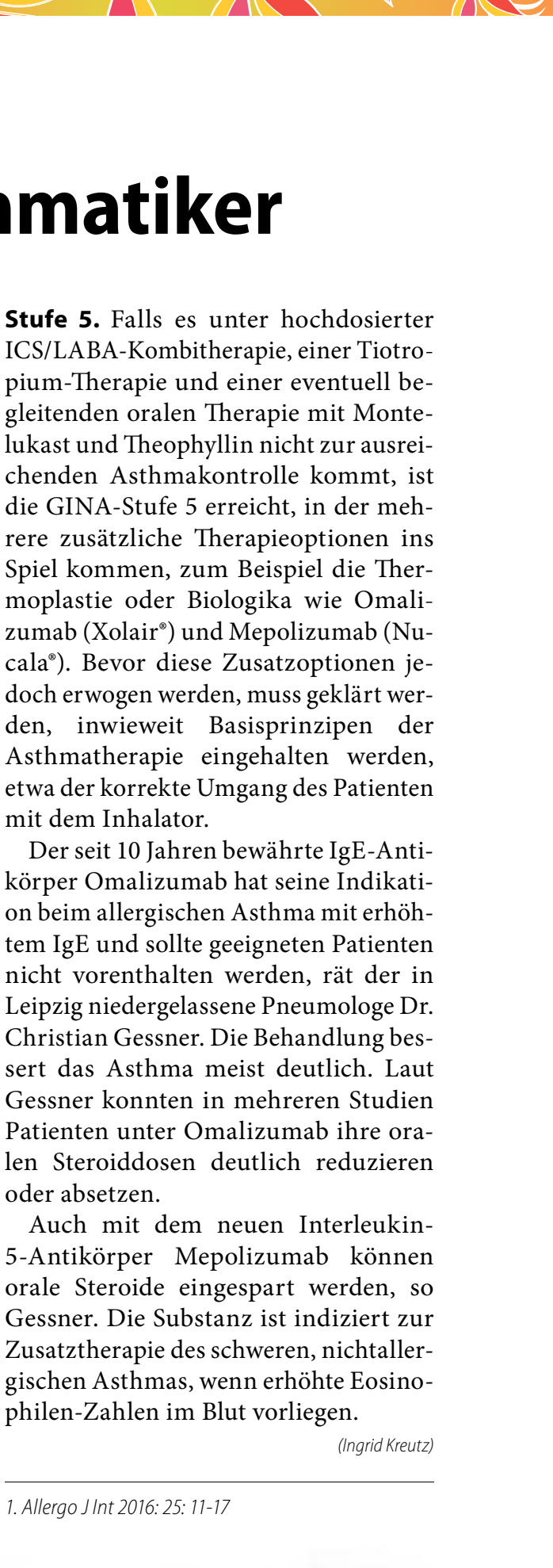

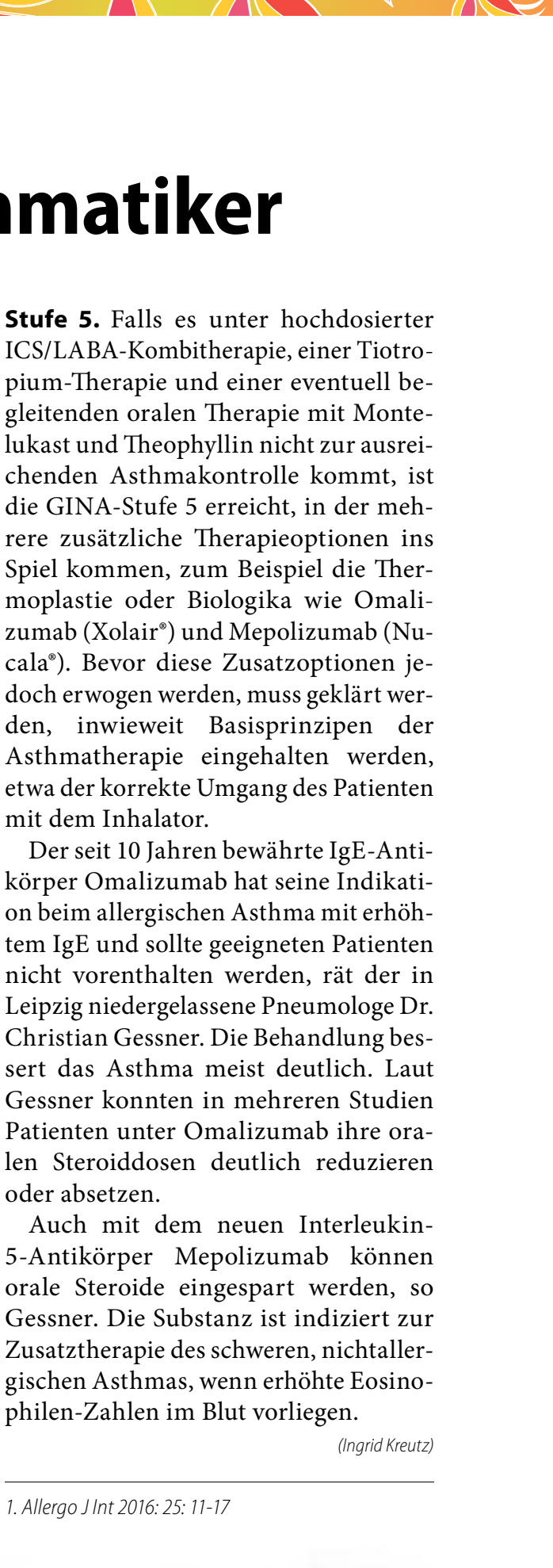

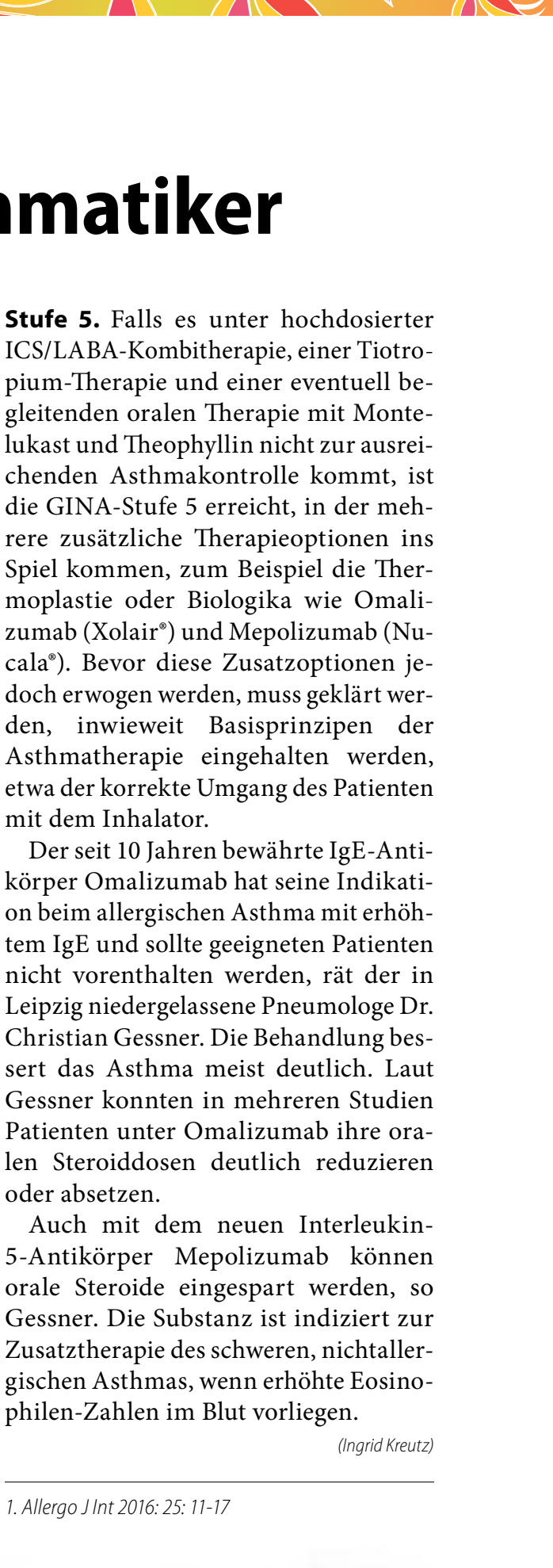

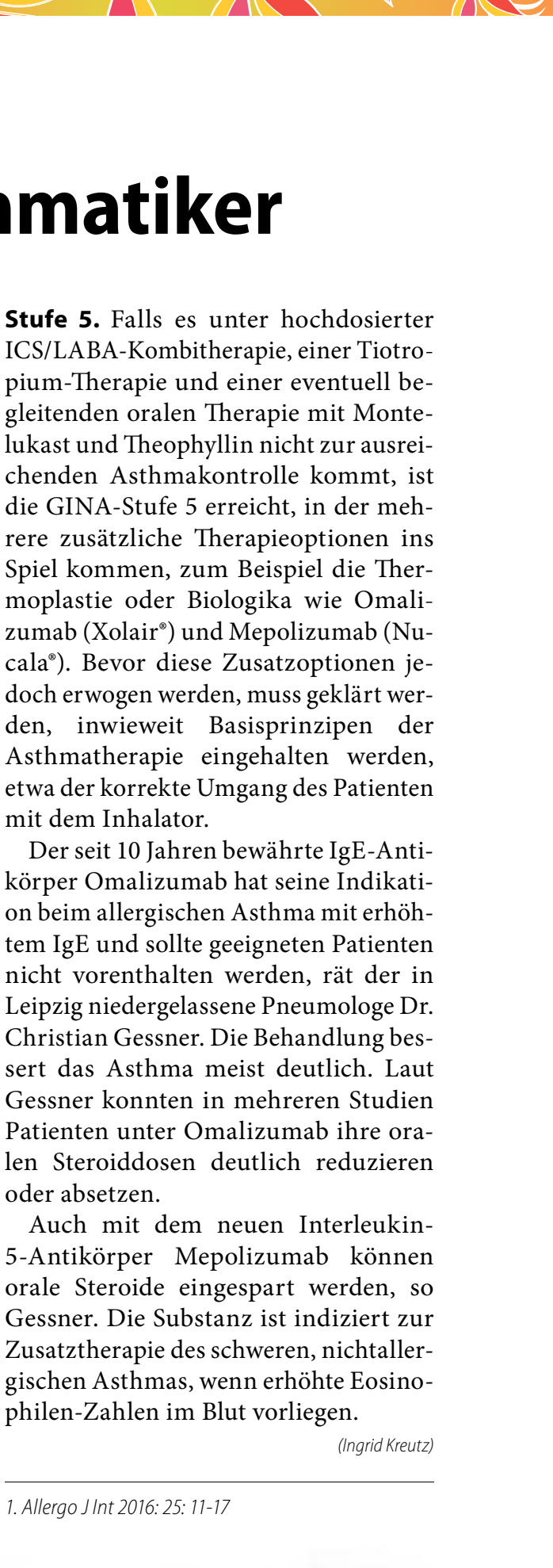

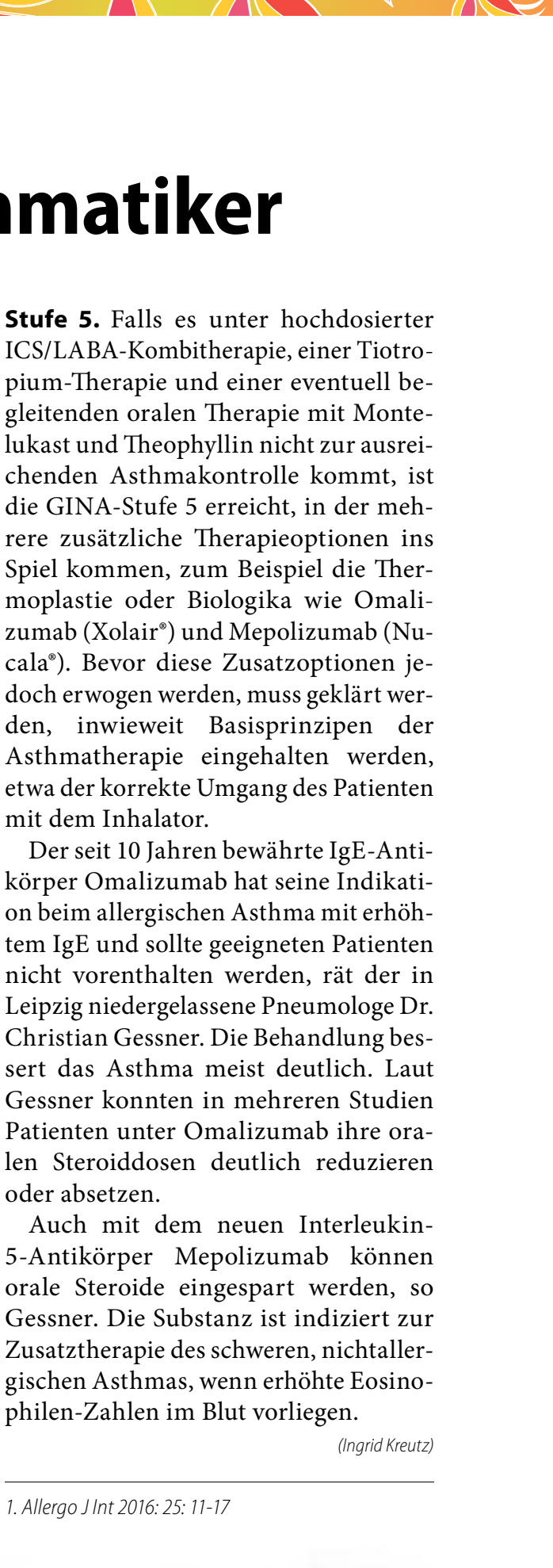

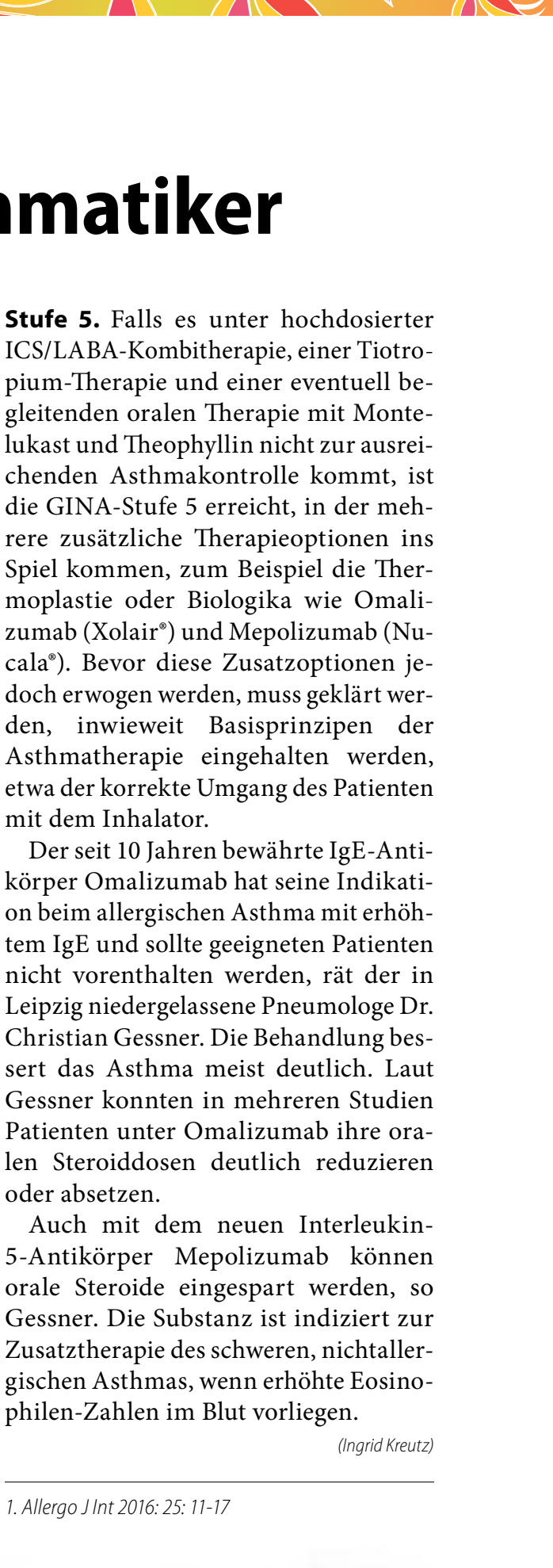

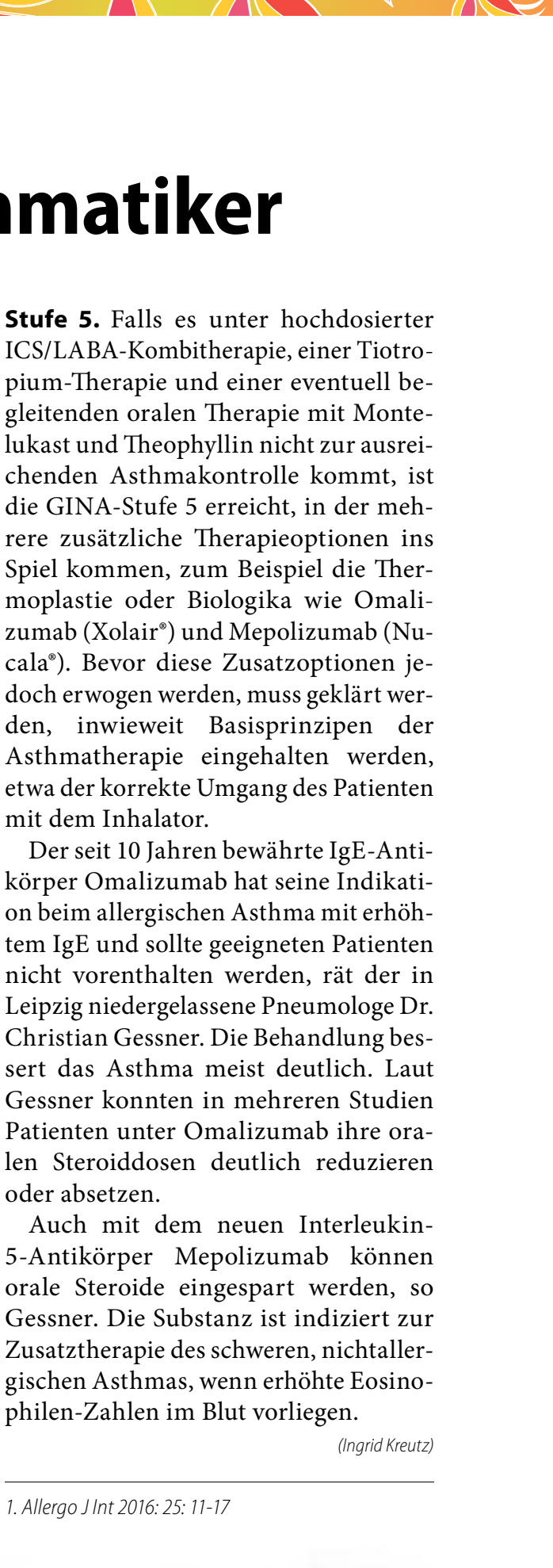

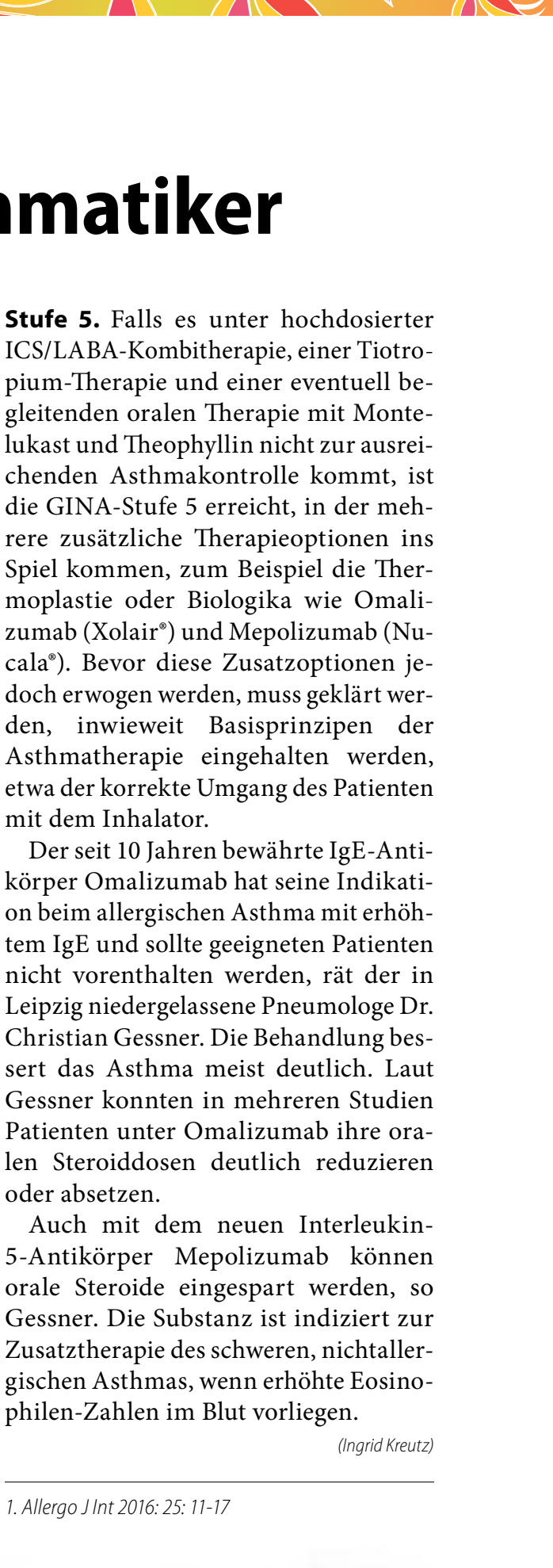

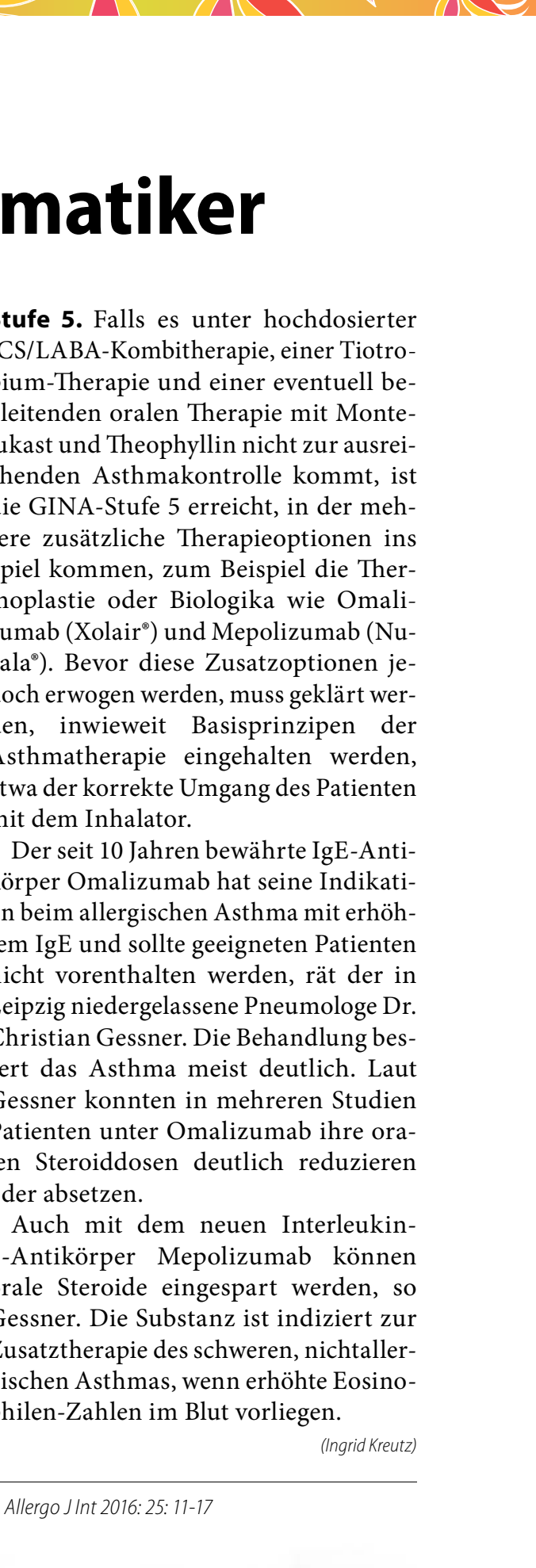

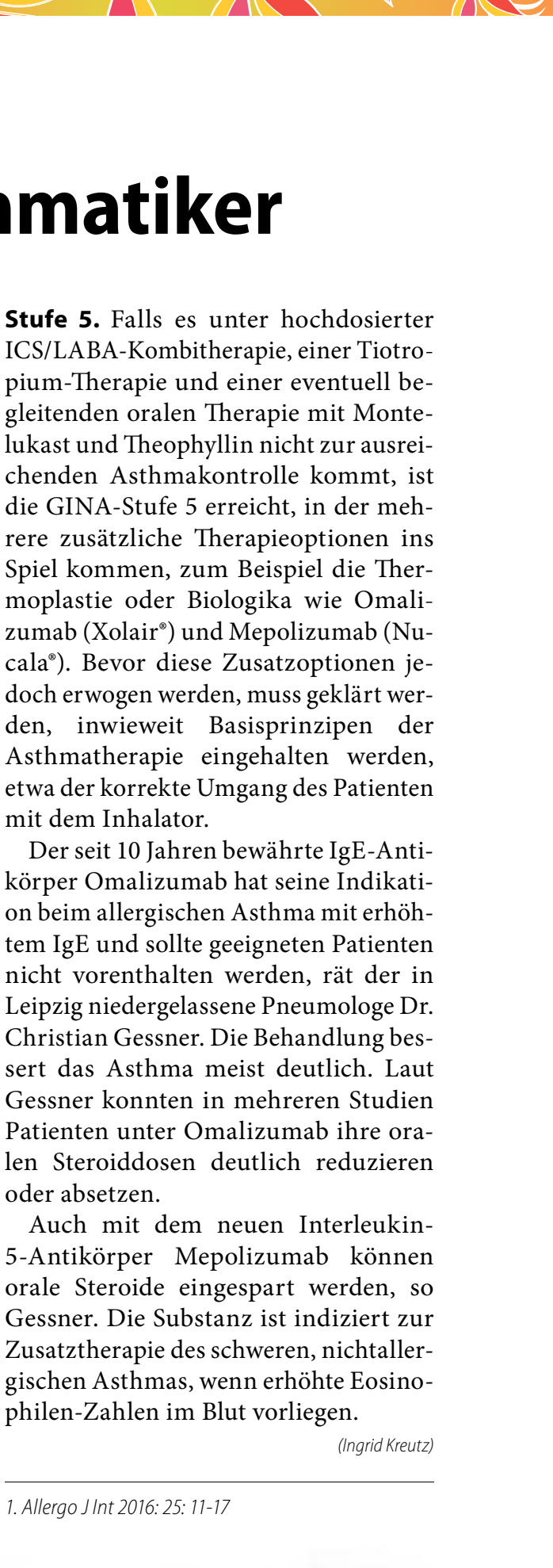

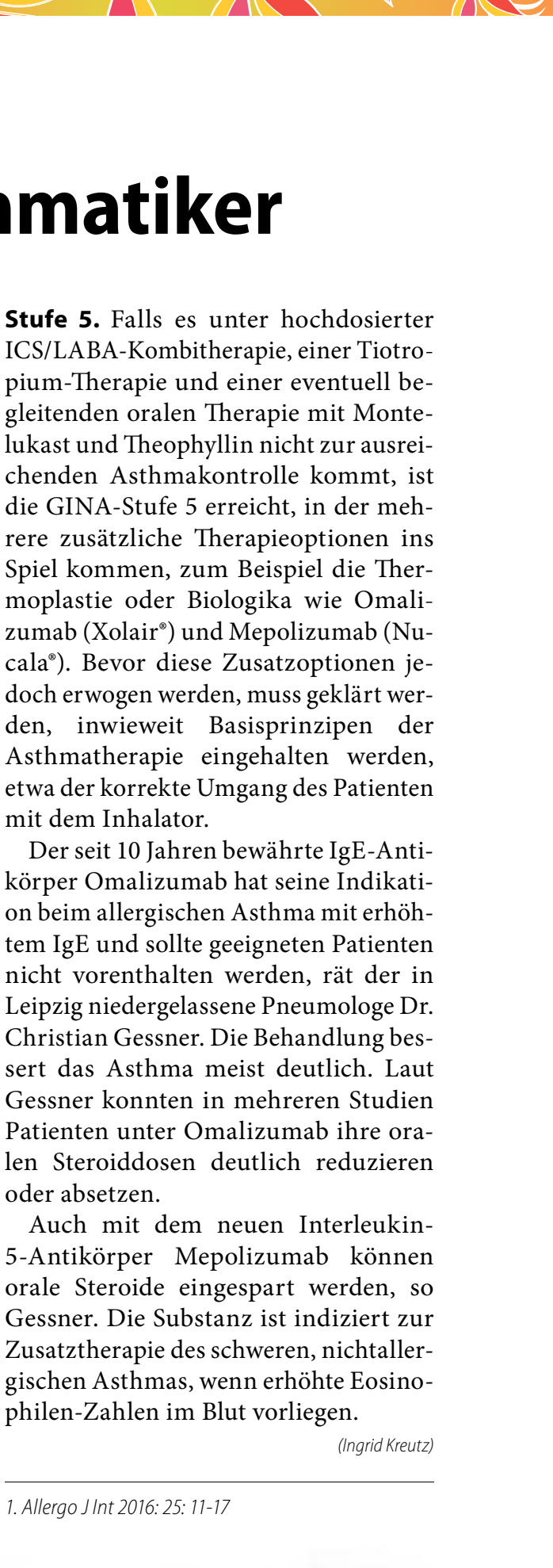

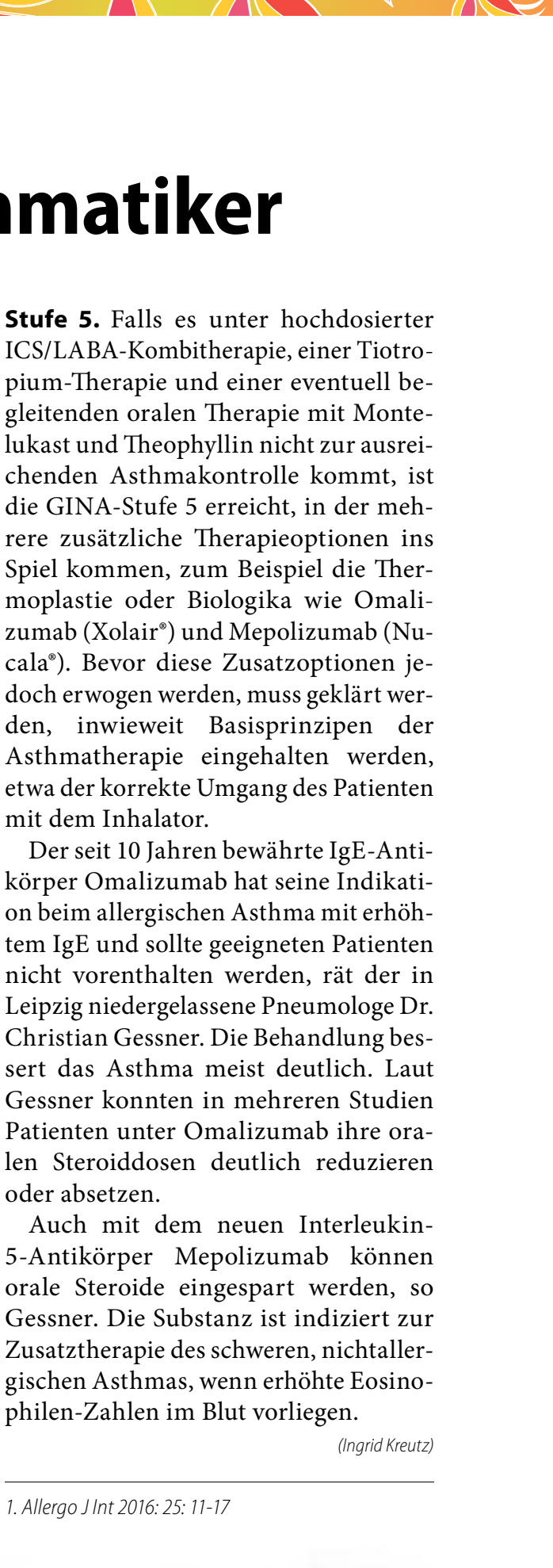

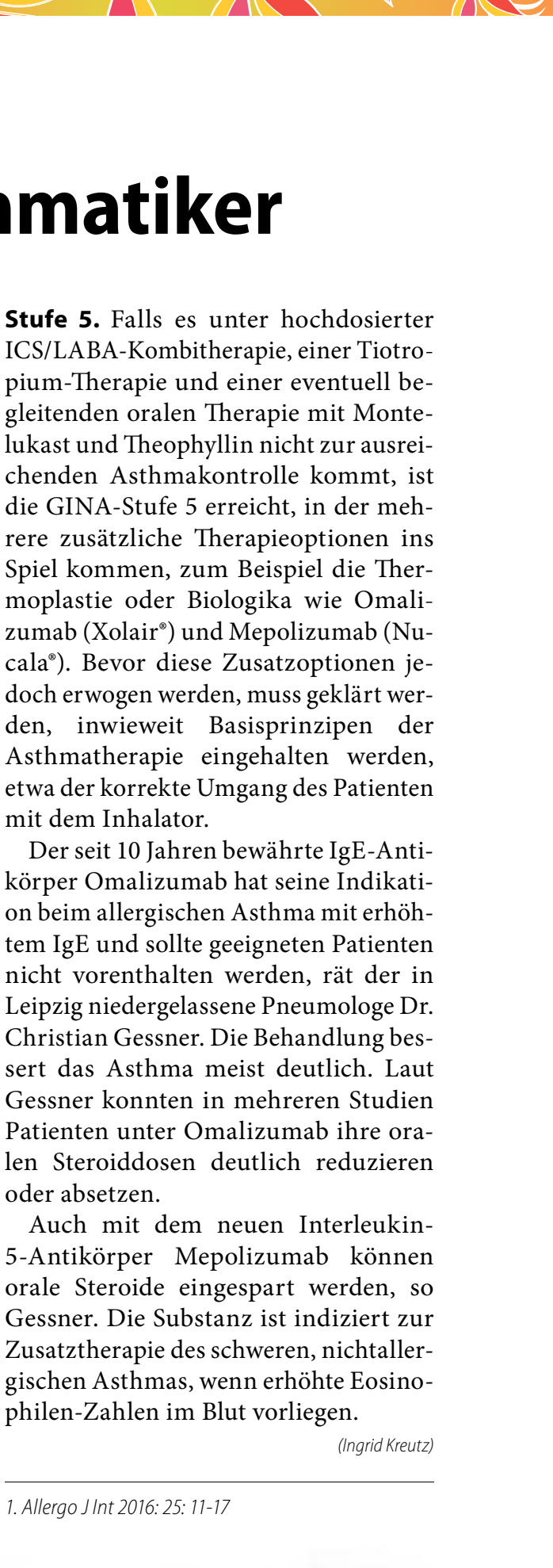

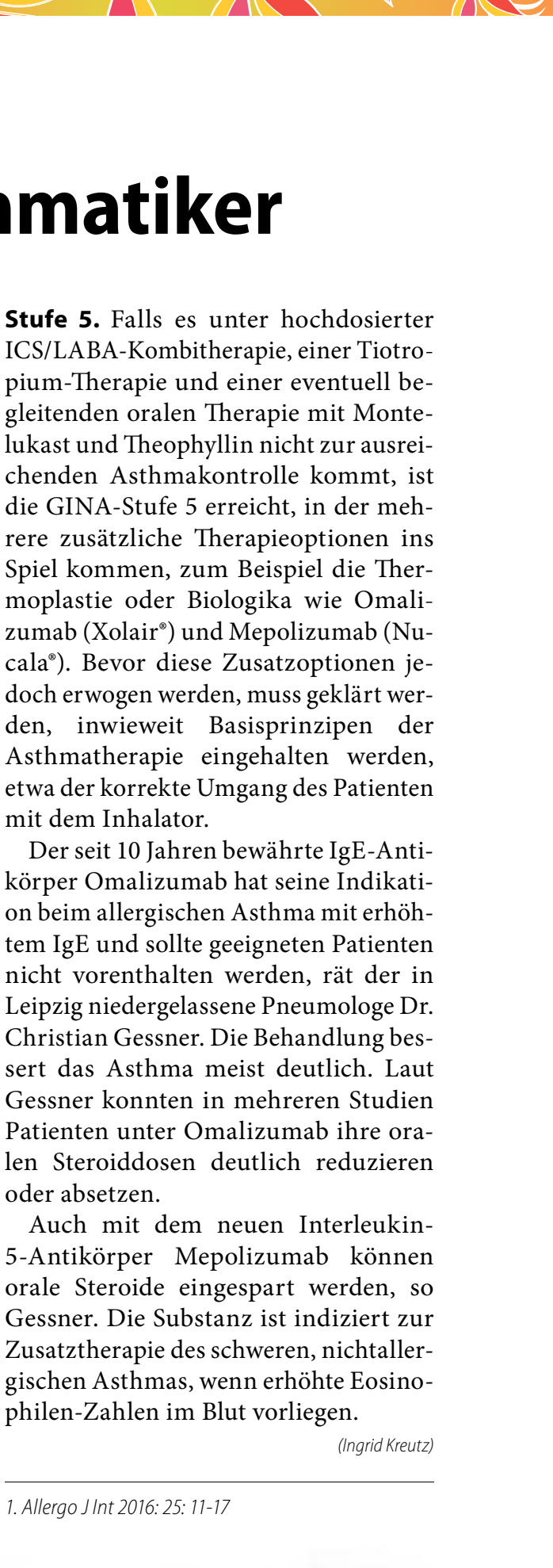

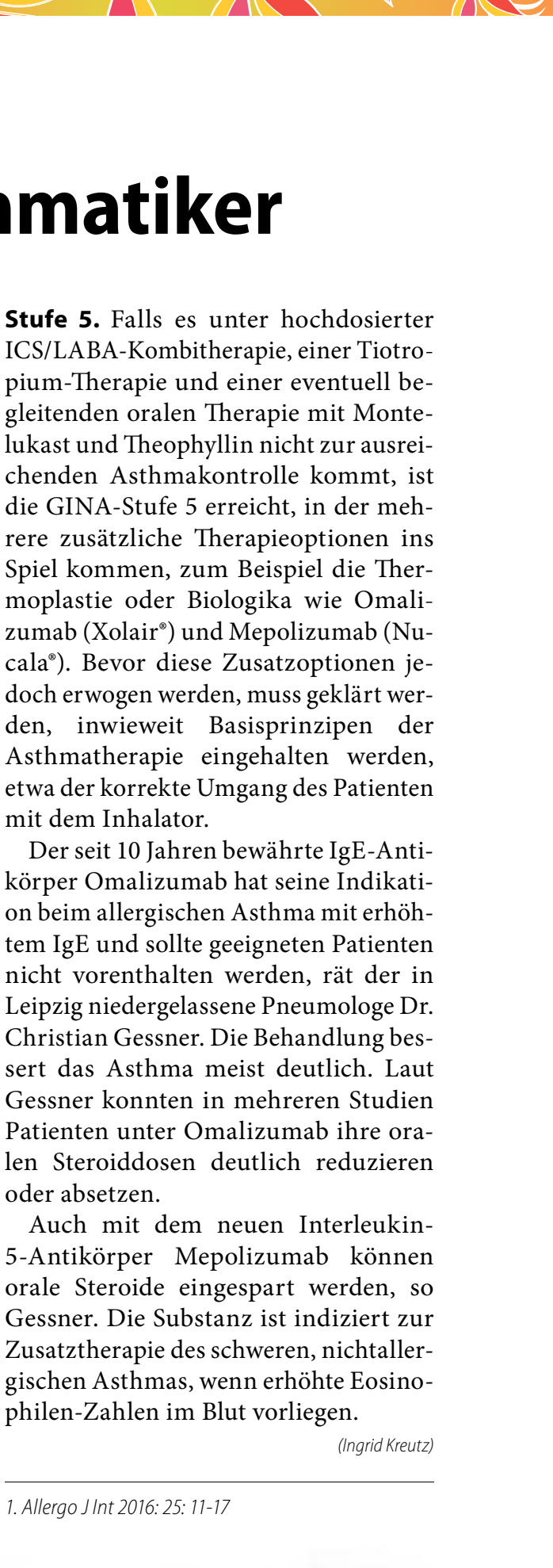

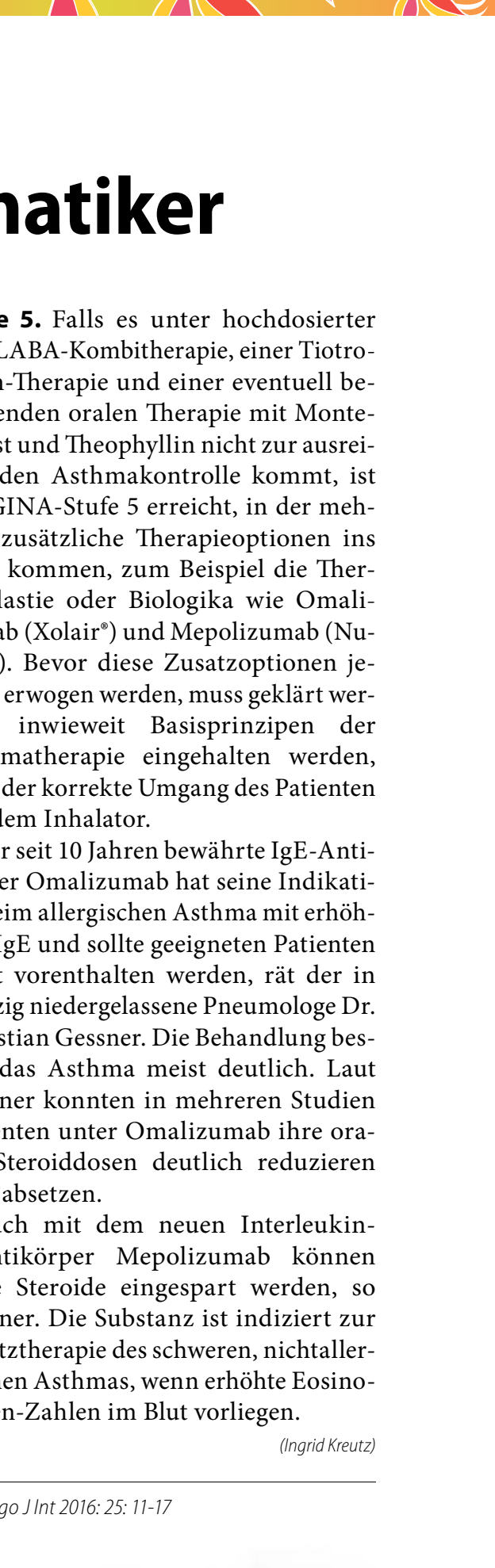

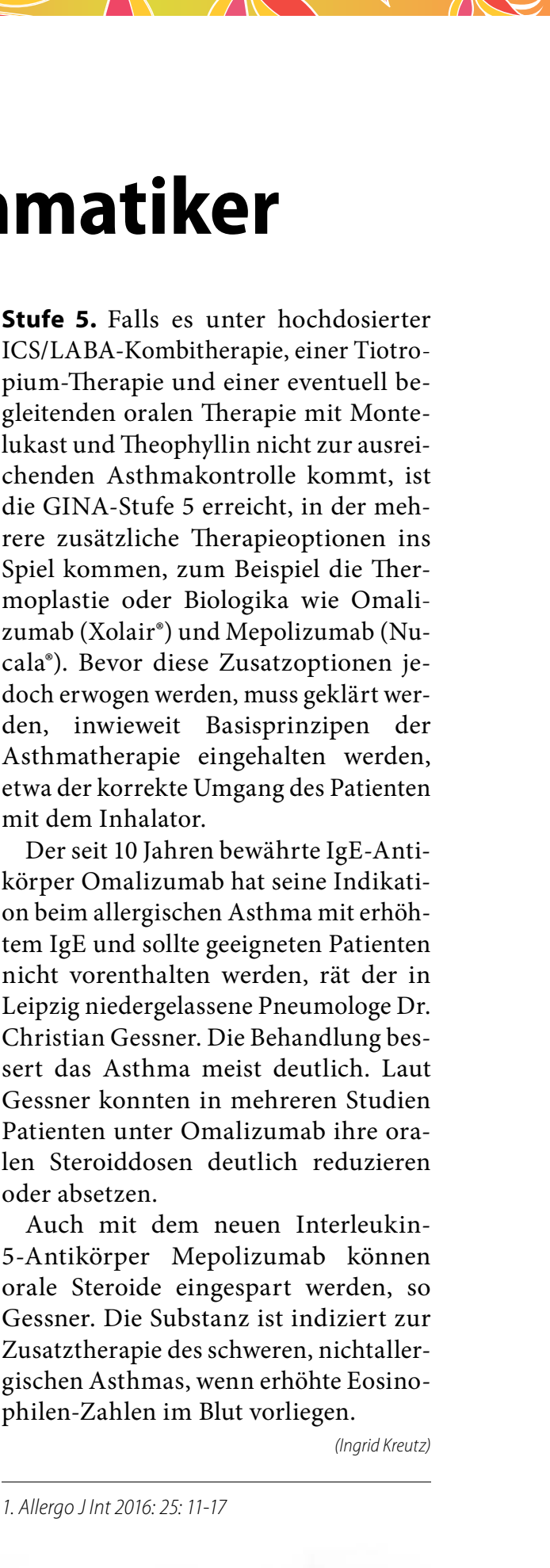

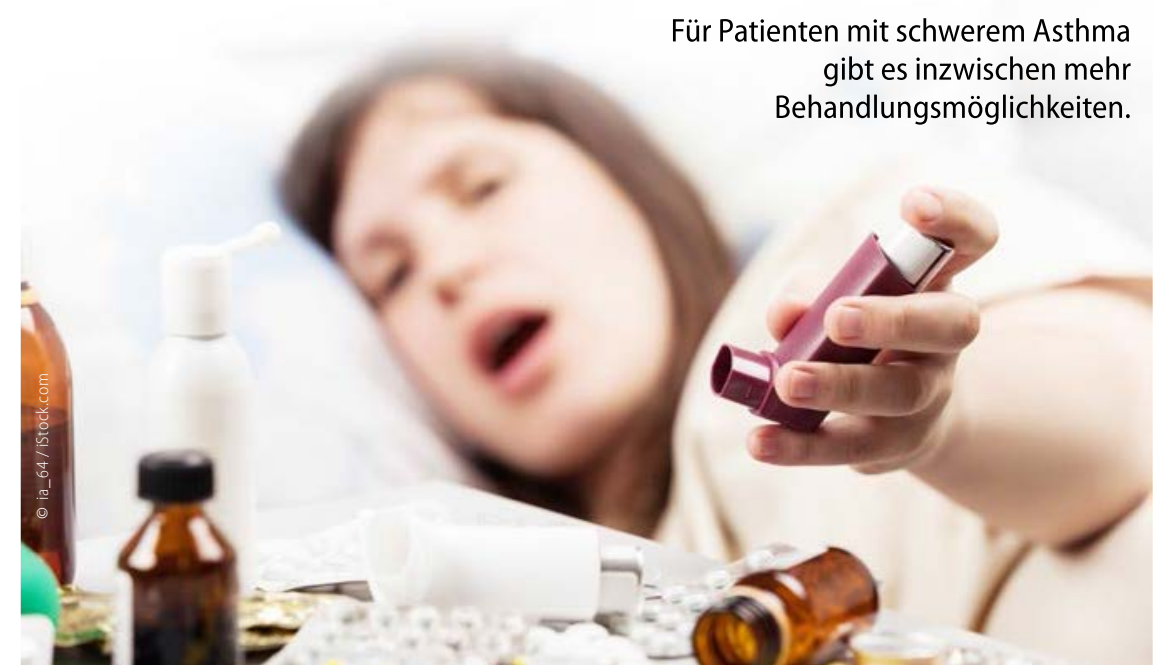

